Reorganização socioeconômica no extremo sul da bahia decorrente da introdução da cultura do eucalipto Thiara Messias de Almeida, Ana Maria Souza dos Santos Moreau,Maurício Santana Moreau, Mônica de Moura Pires, Ednice de Oliveira Fontes, Liliane Matos Góes

\title{
REORGANIZAÇÃO SOCIOECONÔMICA NO EXTREMO SUL DA BAHIA DECORRENTE DA INTRODUÇÃO DA CULTURA DO EUCALIPTO
}

\section{Socio-economic reorganization in the far southern region of Bahia due to the introduction of eucalyptus plantation}

Thiara Messias de Almeida Mestranda em Desenvolvimento Regional e Meio Ambiente - PRODEMA/UESC Graduada em Geografia - UESC thiaramessias@gmail.com

Ana Maria Souza dos Santos Moreau Prof $^{a}$ Titular da Universidade Estadual de Santa Cruz - Dr ${ }^{a}$

Departamento de Ciências Agrárias e Ambientais amoreau@uesc.br

Maurício Santana Moreau

Prof $^{0}$ Titular da Universidade Estadual de Santa Cruz - Dr Departamento de Ciências Agrárias e Ambientais mmoreau@uesc.br

Mônica de Moura Pires Prof $^{\mathrm{a}}$ Titular da Universidade Estadual de Santa Cruz - Dr ${ }^{\mathrm{a}}$

Departamento de Ciências Econômicas mpires@uesc.br

Ednice de Oliveira Fontes Prof $^{a}$ Adjunta da Universidade Estadual de Santa Cruz - Dr $^{\mathrm{a}}$ Departamento de Ciências Agrárias e Ambientais ednice@uesc.br

Liliane Matos Góes Discente do Curso de Geografia da UESC, Bolsista de Iniciação Científica (FAPESB) goes.liliane@yahoo.com.br

Artigo recebido para publicação em 08/06/07 e aceito para publicação em 28/02/08

RESUMO: Este trabalho tem como objetivo analisar a reorganização socioeconômica decorrente da inserção do eucalipto (Eucalyptus grandis) no Extremo Sul da Bahia. Para realização dessa análise fez-se um diagnóstico das principais transformações sociais e econômicas decorrentes da implantação do eucalipto na região, por meio de levantamento bibliográfico e de dados socioeconômicos do IBGE, SEI e Atlas de Desenvolvimento Humano do PNUD. Pode-se constatar que a inserção do eucalipto na região provocou grande crescimento da participação da Bahia no total das exportações do país, dinamizando 
Reorganização socioeconômica no extremo sul da bahia decorrente da introdução da cultura do eucalipto

Thiara Messias de Almeida, Ana Maria Souza dos Santos Moreau,Maurício Santana Moreau,Mônica de Moura Pires,

Ednice de Oliveira Fontes, Liliane Matos Góes

a economia do estado, em especial, a do Extremo Sul, o que pode ser percebido pela elevação do PIB estadual e dos municípios produtores de eucalipto. Quanto à paisagem rural percebe-se uma importante mudança relativa à redução do número de atividades agrícolas e concentração da terra, definindo uma reorganização da estrutura fundiária local. Sob esse novo cenário agrícola observa-se, também, redução no número de empregos gerados no campo, e na participação da agricultura familiar, resultando no aumento da população urbana.

Palavras-chave: eucalipto, celulose, reestruturação produtiva, desenvolvimento.

ABSTRACT: This work aimed to analyze the socio-economic reorganization due to the insertion of Eucalyptus plantation (Eucalyptus grandis) in the far southern region of Bahia. In order to accomplish this analysis, it was done a diagnosis of the main social and economical changes due to the establishment of eucalyptus in the region, using literature retrieval, IBGE's socio-economic data and the UNDP's Atlas of Human Development. It could be noted that the insertion of Eucalyptus plantation in the region has provoked a significant growth of Bahia's exports participation in the national scenario, making the economy more dynamic, especially in the far southern region of Bahia. This impact in the economy may be perceived through the GDP's rising in the State level as far as in the counties that grow eucalyptus grandis. In relation to the rural landscape, it was noted a considerable changing related to a reduction in the number of the agricultural activities and to the land concentration. It defines a reforming framework of the local land ownership structure. Under this new agricultural scenario, it can be noted, for instance, the reduction concerning the number of jobs generated in the rural area, and the activities developed in the context of the family agriculture; what provokes an increasing of urban population.

Keywords: eucalypt, cellulose, productive reform, development.

\section{INTRODUÇÃO}

Na década de 1970 o Governo Federal passou a estimular o plantio de eucalipto no território nacional. Nos anos de 1980, surge na região ExtremoSul da Bahia as primeiras unidades de produção e empresas, atraídas em função de relevantes fatores locacionais, especialmente, segundo os estudos da Superintendência de Estudos Econômicos e Sociais da Bahia - SEI (2002), pelas condições edafoclimáticas, preço da terra, escoamento da produção via porto de Vitória no Espírito Santo e de Ilhéus na Bahia, disponibilidade de mão-de-obra e grandes extensões de terras para implantação dos cultivos de eucalipto (COMPANHIA DE DESENVOLVIMENTO E AÇÃO REGIONAL - CAR, 1994).

Nesse cenário favorável, a produção estadual expande-se, levando a Bahia a despontar e ocupar a segunda posição no setor de produção de papel e celulose do país, destinada ao mercado externo, sendo o Extremo Sul o maior produtor entre as regiões baianas (SOUZA; OLIVEIRA, 2002). Sob tais condições, vêm sendo realizados grandes investimentos tanto pela iniciativa privada quanto pelo Estado no setor, apontando perspectivas de crescimento para os próximos anos, principalmente, na expansão da capacidade produtiva. Atualmente as três maiores empresas instaladas na região são Bahia Sul Celulose, Aracruz Celulose e Veracruz Florestal.

No entanto, segundo a CAR (1994), o aumento na arrecadação municipal é considerado pequeno quando comparado à subtributação e aos incentivos fiscais concedidos a essas empresas. Sob o ponto de vista de geração de emprego e renda, estudos apontam que o impacto desse tipo de empreendimento é relativamente pequeno quando comparado aos agrícolas e de serviços. Porém, a presença de investimentos florestais no Extremo Sul

Sociedade \& Natureza, Uberlândia, 20 (2): 5-18, DEZ. 2008 
Reorganização socioeconômica no extremo sul da bahia decorrente da introdução da cultura do eucalipto Thiara Messias de Almeida, Ana Maria Souza dos Santos Moreau,Maurício Santana Moreau, Mônica de Moura Pires, Ednice de Oliveira Fontes, Liliane Matos Góes

da Bahia tem provocado transformações relevantes no uso da terra, na estrutura social, na organização do espaço regional, na nova lógica de crescimento econômico, que se baseia na apropriação e no consumo da terra, entre outras mudanças.

Segundo Avena (2002), os impactos regionais gerados pela expansão do complexo florestal têm alterado a organização socioeconômica, provocando uma nova lógica de crescimento econômico que resulta na modernização econômica do espaço regional.

Nesse contexto, Gonçalves (1992) salienta que a produção de papel e celulose implica em uma ocupação intensiva do espaço, contribuindo para sua organização, reestruturação de formas sociais, culturais e economicamente vigentes de produção, bem como o uso sustentável dos recursos naturais.

Dessa forma, percebe-se que o cultivo de eucalipto e a produção de celulose e papel vêm produzindo relevantes transformações na organização dos espaços e na estrutura socioeconômica regional. Partindo dessas questões, este trabalho procurou analisar a influência da cultura do eucalipto na reorganização socioeconômica do extremo sul da Bahia.

\section{ÁREA DE ESTUDO}

O Extremo Sul da Bahia localiza-se entre as coordenadas geográficas de $15^{\circ} 45^{\prime}$ a $18^{\circ} 30^{\prime}$ de latitude sul e de $30^{\circ} 50^{\prime}$ a $40^{\circ} 40^{\prime}$ de longitude W.Gr, com uma área de aproximadamente $30.420 \mathrm{~km}^{2}$, representando $5,42 \%$ do total do território estadual, compreendendo vinte e um municípios (CENTRO DE ESTATÍSTICAS E INFORMAÇÕES - CEI, 1992).

Situa-se ao sul do território baiano, em sua área mais afunilada que faz fronteira ao sul com o Espírito Santo, a oeste com Minas Gerais e ao norte com as regiões econômicas baianas Sudoeste e Litoral Sul, sendo a parte leste margeada pelo oceano Atlântico (CAR, 1994).

A região é composta por 21 municípios: Alcobaça, Belmonte, Caravelas, Eunápolis, Guaratinga, Ibirapuan, Itabela, Itagimirim, Itapebi, ltamarajú, ltanhém, Jucuruçu, Lagedão, Medeiros Neto, Mucuri, Nova Viçosa, Porto Seguro, Prado, Santa Cruz de Cabrália, Teixeira de Freitas e Vereda. Destes, foram considerados nesta pesquisa os municípios de: Alcobaça, Belmonte, Caravelas, Eunápolis, Itabela, Itamaraju, Mucuri, Nova Viçosa, Porto Seguro, Prado, Santa Cruz Cabrália e Teixeira de Freitas, vide Figura 01.

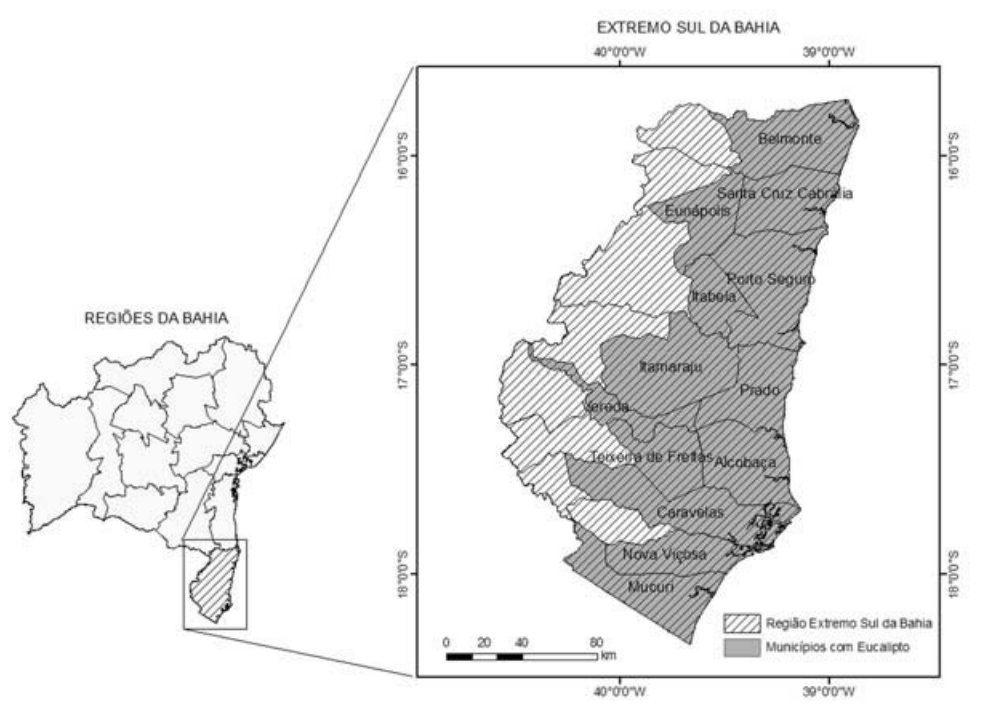

Figura 01 - Recorte do Extremo Sul da Bahia, com destaque para os municípios, com silvicultura, considerados na pesquisa. 
Sua vegetação caracteriza-se por apresentar grande biodiversidade constituindo uma unidade do sistema natural floresta ombrófila densa, sob o domínio de Mata Atlântica. O clima é caracterizado como tropical úmido no litoral e tropical subúmido no interior. As chuvas são bem distribuídas ao longo do ano, com período mais intenso de chuvas entre os meses de novembro a janeiro. A pluviosidade média anual está em torno de $1.100 \mathrm{~m}$, com temperaturas entre $23^{\circ} \mathrm{C}$ e $27^{\circ} \mathrm{C}$ (COUTO, 2006).

\section{PROCEDIMENTOS METODOLÓGICOS}

\section{Para análise das transformações} socioeconômicas decorrentes da introdução de cultivos de eucalipto na região, foram realizados levantamentos bibliográficos e coleta de dados secundários de natureza socioeconômica, junto ao Instituto Brasileiro de Geografia e Estatística (IBGE), à Superintendência de Estudos Econômicos e Sociais da Bahia (SEI) e ao Atlas de Desenvolvimento Humano do Programa das Nações Unidas para o Desenvolvimento (PNUD). As informações coletadas são referentes apenas aos municípios que possuem ligação direta com a atividade analisada.

Para verificar as transformações econômicas ocorridas analisou-se a estrutura fundiária da região, utilizando-se como referência o número e a área de estabelecimentos rurais do período entre 1970-1995/ 96, dos Censos Agropecuários divulgados pelo IBGE, a produção de celulose em toneladas no período de 1990-2004 e o PIB municipal de 1999 e 2003.

Para analisar as transformações sociais na região estudada utilizou-se o PIB per capita municipal dos anos de 1999 e 2003, os dados de população no período de 1970-2000, o número de empregados no campo nos anos de 1970-1995/96 e o IDH municipal de 1991 e 2000.

Através da análise dessas variáveis procurouse identificar os impactos socioeconômicos decorrentes da atividade florestal na região. Os procedimentos metodológicos adotados estão descritos resumidamente na Figura 02.

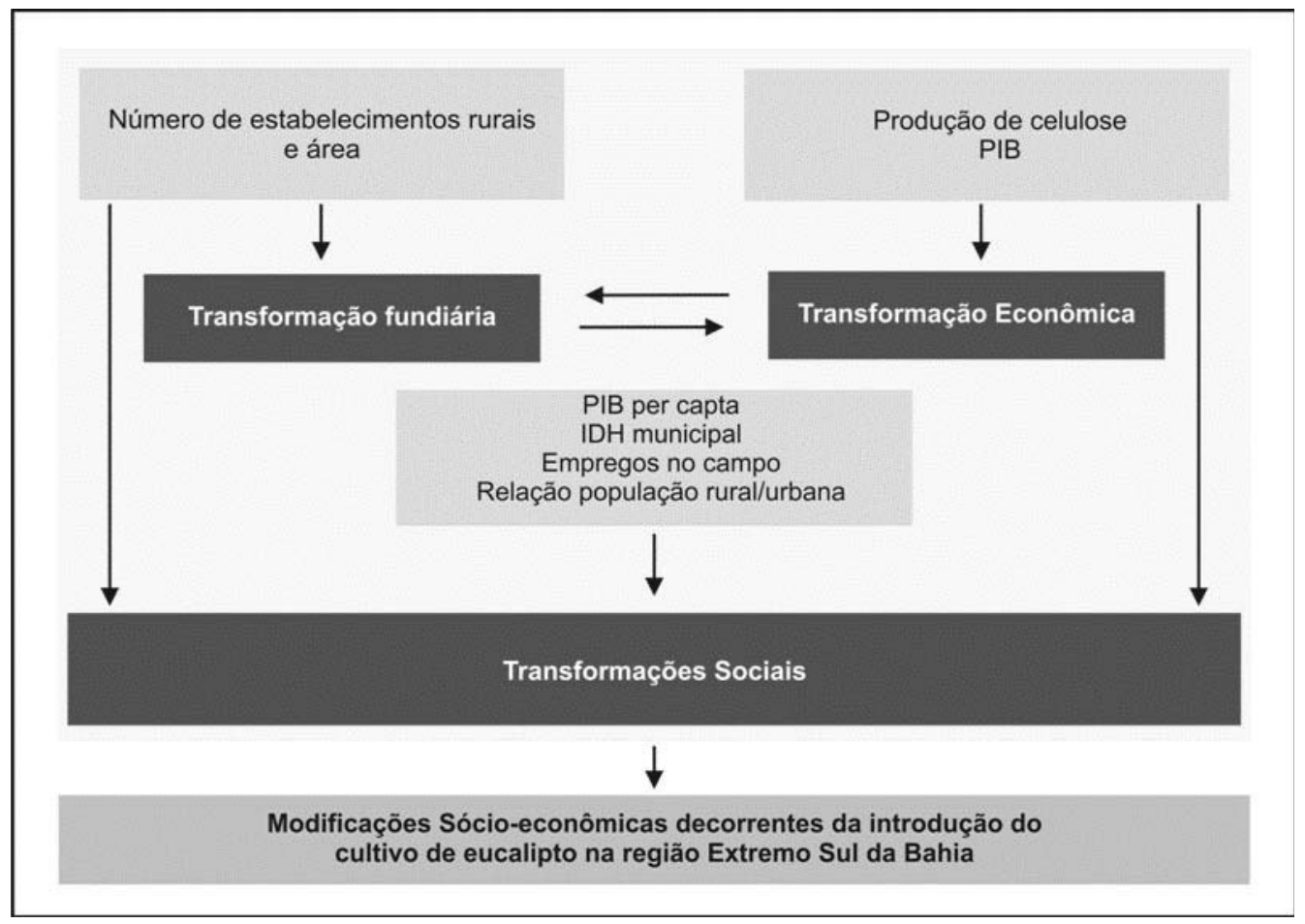

Figura 02: Fluxograma representativo da metodologia utilizada. 
Reorganização socioeconômica no extremo sul da bahia decorrente da introdução da cultura do eucalipto Thiara Messias de Almeida, Ana Maria Souza dos Santos Moreau,Maurício Santana Moreau, Mônica de Moura Pires, Ednice de Oliveira Fontes, Liliane Matos Góes

\section{HISTÓRICO DE OCUPAÇÃO DA REGIÃO}

Desde a época do descobrimento do Brasil a ocupação da região Extremo Sul Baiana vem ocorrendo em todo o território. No entanto, esse processo, ao longo dos séculos, passou por sucessivas transformações sociais e econômicas decorrentes da exploração dos recursos naturais e ocupação de terras.

Desde então, a exploração da madeira da Mata Atlântica tem sido intensiva. Mormente, essa configuração sofre mudanças ao final do século XVIII, início do XIX quando são introduzidos na região o café e o cacau (TEIXEIRA et al., 2006).

Apesar da dinâmica produtiva local, praticamente, até o século XIX, a região encontravase isolada do restante do estado. As explorações agrícolas eram esparsas e as áreas produtivas quase inexpressivas, resultantes, basicamente, de núcleos de povoamento do litoral, mas sem integração regional, situação que perdurou até a década de 1950 (CEI, 1992).

Porém, a partir da década de 1970 as transformações socioeconômicas na região são perceptíveis quando se imprime uma nova dinâmica local. A região se integra à economia estadual e nacional facilitada pela implantação da rodovia federal BR 101, que impulsiona o desenvolvimento regional. Percebe-se então que a conjunção de fatores favoráveis como a implantação de acessos rodoviários, os incentivos fiscais concedidos pelo governo nas décadas de 1970 e 1980 para o reflorestamento estimularam a expansão da cultura do eucalipto e a introdução de empresas de papel e celulose como a Veracel, Bahia Sul e Aracruz, que passam a atender, preponderantemente a demanda do mercado externo. A região também passou a atrair grupos madeireiros do Espírito Santo e de Minas Gerais (CARNEIRO, 1994 e PEDREIRA, 2004).

Se por um lado a cultura do eucalipto na região trouxe mudanças econômicas, por outro sua introdução implicou em sérios prejuízos para os recursos naturais, dentre eles, o solo, a fauna, a flora e os recursos hídricos. Essa atividade também provocou impactos relevantes sobre a sobrevivência da agricultura familiar local em função da ocupação de grandes áreas agricultáveis, inclusive aquelas destinadas à reforma agrária, terras indígenas e no entorno de Unidades de Conservação da Mata Atlântica (SANTOS; SILVA, 2004).

Esse novo panorama regional mostrou-se sobremaneira diferente da silvicultura praticada desde o início da colonização, pois intensificou o processo de devastação da Mata Atlântica (PEDREIRA, 2004).

Atualmente, o cultivo do eucalipto se constitui na atividade mais dinâmica do Extremo Sul baiano, sendo responsável por importantes mudanças socioprodutivas, muito embora atividades tradicionais como a pecuária, agricultura de subsistência e a pesca tenham grande importância na estrutura produtiva da economia regional.

As transformações na ocupação e no uso da terra trouxeram grandes mudanças na paisagem regional, permitindo à região sua inserção na dinâmica econômica nacional e internacional. Além disso, essa nova organização espacial implicou em novas formas de trabalho.

\section{REORGANIZAÇÃO SOCIOECONÔMICA}

A expansão das atividades florestais e agroindustriais propiciou uma inserção competitiva da região nos circuitos dinâmicos da economia nacional e internacional, criando espaços de modernização e propiciando o crescimento econômico da região (SEI, 2002).

Essa nova dinâmica imputou à região um novo padrão de desenvolvimento, tornando-a responsável por mais de $90 \%$ da produção estadual de madeira em tora para papel e celulose, saindo de $349.179 \mathrm{~m}^{3}$ em 1991 para 5.038.564 em 2004, um aumento superior a $1300 \%$ em um período de 13 anos.

A quantidade produzida de madeira de eucalipto (em tora para papel e celulose) vem 
aumentando ao longo do tempo em alguns municípios (Tabela 01), muito embora possam ser verificados ciclos de produção decorrentes do período de plantio e corte da madeira, dado que a produção se inicia, na maioria das vezes, a partir do sexto ano após o plantio.

Nos municípios de Mucuri, Alcobaça, Nova Viçosa e Caravelas concentram-se os maiores plantios, representando cerca de $80 \%$ do total da área plantada na região, onde se localizam as maiores produções, conforme a Tabela 01. Mais recentemente, Eunápolis, Porto Seguro, Santa Cruz de Cabrália começam a despontar nessa atividade, o que pode ser verificado pela produção de eucalipto no município de Eunápolis que atingiu $1.044 .890 \mathrm{~m}^{3} \mathrm{em} 2002$, representando $20,34 \%$ da produção estadual. Porém, Teixeira de Freitas e Belmonte, comparativamente os maiores produtores, possuem certa territorialidade do eucalipto, no entanto, a participação desses municípios no total produzido na Bahia é pouca expressiva, menos de 3\%. É possível constatar que o eucalipto está em processo de expansão dentro da região do Extremo Sul (Tabela 01), tanto em áreas mais tradicionais como pela incorporação de novas áreas.

Segundo Avena (2002), as plantações de eucalipto na Bahia totalizam uma área cultivada de mais de 300.000 ha, na sua maioria de empreendimentos próprios e alguns resultados de fomento florestal com produtores rurais. A Veracruz Florestal, por exemplo, possui cultivos nos municípios de Eunápolis, Santa Cruz Cabrália, Belmonte, Prado e Porto Seguro. A empresa continua expandindo seus plantios, objetivando atingir mais de $70 \mathrm{mil}$ ha de eucalipto (CAR, 1994). Os plantios da Aracruz Celulose concentram-se em Nova Viçosa, Alcobaça, Caravelas, Mucuri, Prado e Teixeira de Freitas, possuindo em Nova Viçosa a maior unidade territorial de produtos de madeira da América Latina (SEI, 2002). Os maciços da Bahia Sul Celulose distribuemse nos municípios de Alcobaça, Caravelas, Mucuri, Nova Viçosa, Teixeira de Freitas e Ibirapoã (LEVY, 1999).

Tabela 01 - Produção de madeira em tora para papel e celulose $\left(\mathrm{m}^{3}\right)$ por município, Bahia, 1990 a 2004.

\begin{tabular}{|c|c|c|c|c|c|c|c|c|c|c|c|c|c|c|c|}
\hline Municípios & 1990 & 1991 & 1992 & 1993 & 1994 & 1995 & 1996 & 1997 & 1998 & 1999 & 2000 & 2001 & 2002 & 2003 & 2004 \\
\hline Alcobaça & - & 75.506 & 325.529 & 408.296 & 511.605 & 395.905 & 209.948 & 133.407 & 1.053 .106 & 973.013 & 1.135 .081 & 1.319 .526 & 609.386 & 116.546 & 350.866 \\
\hline Belmonte & - & - & - & - & - & - & - & - & - & - & - & - & 41.591 & 41.591 & 4.970 \\
\hline Caravelas & - & 273.673 & 446.347 & 720.714 & 474.974 & 606.086 & 536.655 & 565.675 & 1.872 .867 & 1.216 .273 & 1.487 .540 & 644.469 & 315.032 & 1.269 .125 & 808.096 \\
\hline Eunápolis & - & - & - & - & - & - & - & - & - & - & - & - & 1.044 .890 & 378.157 & 52.776 \\
\hline Itabela & - & - & - & - & - & - & - & - & - & - & - & - & 519.666 & 519.666 & - \\
\hline Itamaraju & - & - & - & - & - & - & - & - & - & - & - & - & - & - & - \\
\hline Mucuri & - & - & 53.321 & 108.171 & 11.510 & 19.700 & 13.262 & 596.948 & 1.245 .806 & 2.204 .254 & 2.643 .836 & 1.186 .784 & 699.199 & 886.529 & 1.518 .050 \\
\hline Nova Viçosa & - & - & 301.519 & 463.098 & 614.760 & 691.881 & 953.620 & 629.317 & 513.781 & 713.822 & 462.386 & 463.686 & 1.327 .204 & 1.678 .760 & 662.609 \\
\hline Porto Seguro & & & & & & & & & & & & & 190.971 & 190.971 & 767.182 \\
\hline Prado & - & - & - & - & - & - & 6.431 & - & - & - & - & 29.198 & - & - & - \\
\hline Santa Cruz Cabrália & - & - & - & - & - & - & - & - & - & - & - & - & 524.241 & 524.241 & 816.544 \\
\hline Teixeira de Freitas & - & - & 6.315 & 1.344 & 382 & 39.194 & 1.218 & 30.414 & 24.296 & 390 & 19.392 & - & 93.387 & - & \\
\hline Bahia & 121.707 & 352.088 & 1.609 .790 & 1.912 .501 & 2.186 .702 & 2.646 .807 & 2.265 .798 & 2.879 .703 & 5.753 .001 & 5.707 .117 & 11.436 .517 & 5.133 .429 & 5.135 .648 & 6.219 .340 & 5.318 .263 \\
\hline
\end{tabular}

Pode-se observar que esses investimentos permitiram mudanças relevantes no Produto Interno Bruto (PIB) desses municípios (Tabela 02). Observase um crescimento do PIB, em todos os municípios, comparando-se os anos de 1999 e 2003, especialmente em Itabela e Eunápolis que apresentam as maiores taxas de crescimento, superiores a $100 \%$. 
Reorganização socioeconômica no extremo sul da bahia decorrente da introdução da cultura do eucalipto Thiara Messias de Almeida, Ana Maria Souza dos Santos Moreau,Maurício Santana Moreau, Mônica de Moura Pires, Ednice de Oliveira Fontes, Liliane Matos Góes

Tabela 02 - PIB por Município do Extremo Sul da Bahia 1999-2003. Produto Interno Bruto a preços correntes em milhões R\$

\begin{tabular}{lccc}
\hline Municípios & $\mathbf{1 9 9 9}$ & $\mathbf{2 0 0 3}$ & Taxa de crescimento (\%) \\
\hline Alcobaça & 61,3 & 92,32 & 51 \\
Belmonte & 38,14 & 67,91 & 78 \\
Caravelas & 70,11 & 102,68 & 46 \\
Eunápolis & 213,65 & 437,71 & 105 \\
Itabela & 44,78 & 95,68 & 114 \\
Itamaraju & 143,39 & 239,16 & 67 \\
Mucuri & 472,78 & 886,22 & 87 \\
Nova Viçosa & 73,89 & 144,06 & 95 \\
Porto Seguro & 224,93 & 313,25 & 39 \\
Prado & 79,22 & 152,6 & 93 \\
Santa Cruz Cabrália & 50,38 & 67,57 & 34 \\
Teixeira de Freitas & 244,96 & 391,05 & 60 \\
\hline
\end{tabular}

Fonte: SEI/BAHIA, www.sei.ba.gov.br (2006).

No decorrer do tempo, o aumento da produção ocorre em intervalos que variam de um a três anos e que, posteriormente há queda. Tal fato está associado ao ciclo produtivo do eucalipto. Diferentemente do que ocorre nos países de clima frio, onde a indústria florestal é concentrada, com período de rotação do eucalipto variando entre 25 a 80 anos, no Brasil é possível realizar o corte com apenas sete anos, com produtividade média de $34 \mathrm{~m}^{3}$, sendo que na Bahia essa produtividade atinge valores entre 42 e $50 \mathrm{~m}^{3}$ (SEI, 2002).

Na Tabela 03 tem-se o valor do PIB per capita da região, em que se verifica que o impacto do crescimento do PIB total em relação à população foi mais expressivo em Itabela, Eunápolis, Belmonte e Nova Viçosa.

Tabela 03 - PIB per capta por Município do Extremo Sul da Bahia 1999-2003 em R\$

\begin{tabular}{lccc}
\hline Município & $\mathbf{1 9 9 9}$ & $\mathbf{2 0 0 3}$ & Taxa de crescimento (\%) \\
\hline Alcobaça & $2.963,48$ & $4.056,09$ & 37 \\
Belmonte & $1.895,07$ & $3.531,94$ & 86 \\
Caravelas & $3.497,26$ & $4.987,50$ & 43 \\
Eunápolis & $2.558,66$ & $4.892,10$ & 91 \\
Itabela & $1.754,65$ & $3.456,84$ & 97 \\
Itamaraju & $2.325,24$ & $3.732,32$ & 61 \\
Mucuri & $17.138,42$ & $27.535,04$ & 61 \\
Nova Viçosa & $2.325,18$ & $4.158,64$ & 79 \\
Porto Seguro & $2.420,12$ & $2.614,84$ & 8 \\
Prado & $3.009,73$ & $5.445,77$ & 81 \\
Santa Cruz Cabrália & $2.180,97$ & $2.198,64$ & 1 \\
Teixeira de Freitas & $2.300,25$ & $3.368,47$ & 46 \\
\hline
\end{tabular}

Fonte: SEI/BAHIA, www.sei.ba.gov.br (2006).

O aumento do PIB total e per capita nesses municípios não significa que a população se beneficiou de maneira uniforme com tal crescimento e que houve uma mudança no padrão de vida na região. Ademais, à exceção do município de Mucuri, todos os outros municípios apresentaram PIB per 
capita inferior à média estadual que foi de $\mathrm{R} \$$ $7.630,93$, em 2002.

A partir da análise do PIB total per capita (utilizada como uma proxy da renda da população) fica evidente a situação de pobreza que esses municípios se encontram. Nota-se que as atividades econômicas presentes foram incapazes de promover o desenvolvimento social eqüitativo para a população do Extremo Sul da Bahia (INSTITUTO OBSERVATÓRIO SOCIAL - IOS, 2005). A atividade florestal não provocou um impacto social positivo equivalente ao montante de capital empregado, o que pode, em certa medida, ser confirmado pelos valores de IDH dos municípios da região.

Esse índice serve como medida razoável para identificar o nível de desenvolvimento econômico de regiões. Sabe-se que quanto maior for o IDH e a renda per capita de um município, maior tende a ser o desenvolvimento social da região.

$\mathrm{Na}$ Tabela 04, verifica-se que as menores taxas de crescimento do IDH, comparando-se os anos de 1991 e 2000, ocorreram nos municípios de Eunápolis, (16\%), Teixeira de Freitas (17\%) e Itamaraju (17\%), enquanto as maiores taxas foram encontradas nos municípios de Caravelas (37\%) e Mucuri (31\%). Os municípios de Prado, Alcobaça e Belmonte, também cresceram, mas, em percentual menor entre 25 e $30 \%$, respectivamente.

Embora seja observado um crescimento no IDH em todos os municípios pesquisados, os mesmos ainda encontram-se abaixo da média nacional $(0,766)$ no ano de 2000. Os municípios de Teixeira de Freitas, Santa Cruz Cabrália, Porto Seguro, Mucuri e Eunápolis, apresentaram valores iguais e, ou acima da média estadual. Com base na Tabela 04, verificase ainda que em 1991 apenas dois municípios (Teixeira de Freitas e Eunápolis), apresentaram IDH acima da média estadual.

Levando-se em consideração a abordagem econômica e social do IDH, PIB per capita, longevidade e educação, pode-se afirmar que o incremento das atividades florestais e até mesmo as atividades econômicas tradicionais da região não foram suficientes para gerar transformações sociais significativas que contribuíssem na melhoria das condições de vida da população dos municípios objeto desta pesquisa.

Tabela 04 - Índice de Desenvolvimento Humano Municipal (IDHM) dos municípios do Extremo Sul, Bahia, Brasil 1991-2000

\begin{tabular}{lccc}
\hline Município & $\mathbf{1 9 9 1}$ & $\mathbf{2 0 0 0}$ & Taxa de crescimento (\%) \\
\hline Alcobaça & 0,506 & 0,637 & 26 \\
Belmonte & 0,493 & 0,618 & 25 \\
Caravelas & 0,488 & 0,667 & 37 \\
Eunápolis & 0,607 & 0,704 & 16 \\
Itabela & 0,524 & 0,637 & 22 \\
Itamaraju & 0,556 & 0,650 & 17 \\
Mucuri & 0,525 & 0,690 & 31 \\
Nova Viçosa & 0,548 & 0,658 & 20 \\
Porto Seguro & 0,590 & 0,699 & 18 \\
Prado & 0,512 & 0,665 & 30 \\
Santa Cruz Cabrália & 0,560 & 0,688 & 23 \\
Teixeira de Freitas & 0,598 & 0,698 & 17 \\
\hline Bahia & $\mathbf{0 , 5 9 0}$ & $\mathbf{0 , 6 8 8}$ & $\mathbf{1 7}$ \\
Brasil & $\mathbf{0 , 6 9 6}$ & $\mathbf{0 , 7 6 6}$ & $\mathbf{1 0}$ \\
\hline
\end{tabular}

Fonte: Atlas de Desenvolvimento Humano, 2000. 
Reorganização socioeconômica no extremo sul da bahia decorrente da introdução da cultura do eucalipto Thiara Messias de Almeida, Ana Maria Souza dos Santos Moreau,Maurício Santana Moreau, Mônica de Moura Pires, Ednice de Oliveira Fontes, Liliane Matos Góes

Segundo estudo do Instituto Observatório Social (2005), essa situação está relacionada à incapacidade dos ciclos econômicos, pelos quais passou a região, em estruturar uma economia diversificada e integrada, pois, as novas atividades econômicas, apesar de compensarem parcialmente o declínio dos ciclos anteriores, não foram capazes de gerar renda suficiente que permitisse alavancar, sobremaneira, a economia desses municípios e provocassem uma alteração mais relevante nos indicadores sociais.

Percebe-se, porém, que os empreendimentos de celulose e papel alteraram a paisagem regional e promoveram uma nova organização do espaço, principalmente, dos fatores socioeconômicos, imputando ao Extremo Sul da Bahia, uma nova lógica de crescimento econômico (CAR, 1994).

Assim, considerando o crescente avanço das áreas de reflorestamento e observando a grande produção alcançada na região, pode-se fazer uma correlação direta dessa produção com a disponibilidade de terras no espaço rural. Pois, sabendo-se que as empresas do ramo de papel e celulose necessitam de grandes áreas para o reflorestamento, é interessante salientar que transformações são observadas na estrutura agrária, fundiária e produtiva dos municípios do Extremo Sul baiano.

Neste contexto, a ocupação intensiva de vastas áreas rurais, através da implantação de florestas, conquistou terras antes destinadas à agropecuária, em especial pequenas propriedades com culturas alimentares (MIRANDA, 1992 apud CAR, 1994).

Tal fato pode ser percebido, conforme a Tabela 05 pela diminuição tanto do número de estabelecimentos rurais como da área das pequenas propriedades nos últimos 30 anos. De 1970 a 1995/ 96 o número de estabelecimentos com menos de 50 ha passou de 6.746 para 4.232 , esses números expressam uma redução de $37,26 \%$ e de $57,24 \%$ na área. Em contrapartida, os estabelecimentos com mais de 10.000 ha passaram de 2 para 4 no mesmo período. Contudo, foram os estabelecimentos com tamanho entre 50-100 ha que sofreram as maiores reduções (72,88\% nos estabelecimentos e $74,41 \%$ na área).

Tabela 05 - Número e área de estabelecimentos, Extremo Sul da Bahia, 1970, 1975, 1985, 1995/1996

\begin{tabular}{|c|c|c|c|c|c|c|c|c|c|c|}
\hline \multicolumn{2}{|c|}{ Grupos de área } & \multirow{2}{*}{$\begin{array}{r}\begin{array}{r}\text { Menos } \\
\text { de } \mathbf{5 0} \text { ha }\end{array} \\
6.746\end{array}$} & \multirow{2}{*}{$\begin{array}{r}\begin{array}{r}\mathbf{5 0 - 1 0 0} \\
\text { ha }\end{array} \\
3.443\end{array}$} & \multirow{2}{*}{$\begin{array}{r}\begin{array}{r}\mathbf{1 0 0 - 5 0 0} \\
\mathbf{h a}\end{array} \\
1.242\end{array}$} & \multirow{2}{*}{$\begin{array}{r}\mathbf{5 0 0}- \\
\mathbf{1 0 0 0} \text { ha } \\
274\end{array}$} & \multirow{2}{*}{$\begin{array}{r}\begin{array}{r}\mathbf{1 0 0 0}- \\
\mathbf{5 0 0 0} \text { ha }\end{array} \\
141\end{array}$} & \multirow{2}{*}{$\begin{array}{r}\begin{array}{r}\mathbf{5 0 0 0}- \\
\mathbf{1 0 0 0 0} \text { ha }\end{array} \\
8\end{array}$} & \multirow{2}{*}{$\begin{array}{r}10000 \text { e } \\
\text { mais ha }\end{array}$} & \multirow{2}{*}{$\begin{array}{r}\text { SD* } \\
-\end{array}$} & \multirow{2}{*}{$\begin{array}{r}\text { Total } \\
13.856\end{array}$} \\
\hline 1970 & No Estabelecimento & & & & & & & & & \\
\hline & Área & 155.753 & 226.911 & 583.916 & 173.995 & 243.189 & 54.808 & 86.975 & - & 1.525 .547 \\
\hline \multirow[t]{2}{*}{1975} & No Estabelecimento & 5.979 & 2.756 & 3.033 & 305 & 179 & 11 & 3 & - & 12.266 \\
\hline & Área & 134.175 & 180.636 & 570.435 & 199.202 & 303.239 & 80.915 & 38.645 & - & 1.507 .247 \\
\hline \multirow[t]{2}{*}{1980} & No Estabelecimento & 7.103 & 2.012 & 2.327 & 272 & 215 & 10 & 4 & 77 & 12.020 \\
\hline & Área & 122.008 & 135.586 & 464.118 & 182.885 & 385.933 & 66.879 & 54.668 & - & 1.412 .047 \\
\hline \multirow[t]{2}{*}{1985} & No Estabelecimento & 7.982 & 1.986 & 2.400 & 385 & 257 & 13 & 7 & 1 & 13.030 \\
\hline & Área & 140.367 & 132.674 & 494.643 & 257.204 & 464.306 & 85.974 & 100.814 & - & 1.675 .982 \\
\hline \multirow[t]{2}{*}{$1995 / 96$} & No Estabelecimento & 4.232 & 881 & 1.239 & 209 & 143 & 9 & 4 & - & 6.717 \\
\hline & Área & 66.595 & 61.518 & 268.839 & 143.366 & 241.464 & 55.103 & 88.410 & - & 925.296 \\
\hline
\end{tabular}

Nota: * Sem declaração.

Fonte: IBGE, Censo Agropecuário, 1970, 1975, 1980, 1985, 1995/96 apud Pedreira (2004).

Pode-se verificar, Tabela 05, que em 1995/96 os estabelecimentos com menos de 50 ha e na faixa de 50-100 ha representavam $64 \%$ e $13 \%$, respectivamente, ou seja, $77 \%$ do total, no entanto a sua área correspondia a apenas $17 \%$ do total.
O número de estabelecimentos rurais com tamanho entre $100-500$ ha em 1970 representava $10 \%$ do total compreendendo 50\% da área. Em 1995/96 esses estabelecimentos representavam apenas $18 \%$ com $29 \%$ da área na região. 
Reorganização socioeconômica no extremo sul da bahia decorrente da introdução da cultura do eucalipto

Thiara Messias de Almeida, Ana Maria Souza dos Santos Moreau,Maurício Santana Moreau,Mônica de Moura Pires,

Ednice de Oliveira Fontes, Liliane Matos Góes

Enquanto isso, ocorreu o crescimento no número de estabelecimentos com mais de 500 ha, entre 1970 a 1995 , indicando um processo de concentração de terras na região, fruto de atividades agrícolas cada vez mais exigentes em escala de produção.

Sendo assim, a questão relativa à concentração fundiária permite afirmar que o período mais acentuado de concentração de terras na região coincide com a entrada das empresas madeireiras no Extremo Sul, a exemplo do que aconteceu no país, pela incorporação dos menores estabelecimentos pelos maiores e de novas áreas (SILVA, 1993). Nesse contexto, a expansão de atividades extensivas, tais como a pecuária e o reflorestamento, são apontadas como principais causas da concentração fundiária e do êxodo rural na região (IOS, 2005).

Posto isso, verifica-se que as transformações na economia da região decorrentes da implantação do cultivo do eucalipto causaram também reestruturações do emprego na área rural, nos municípios onde foram desenvolvidas essas atividades.

Percebe-se, conforme Figura 03, que no período de 1970-1985 o número de empregos permanentes no campo cresceu, no entanto, essa tendência muda nos períodos subseqüentes. No ano passou de 20.249 em 1985 para 8.914 em 1995, representando uma queda de $127 \%$ no emprego.

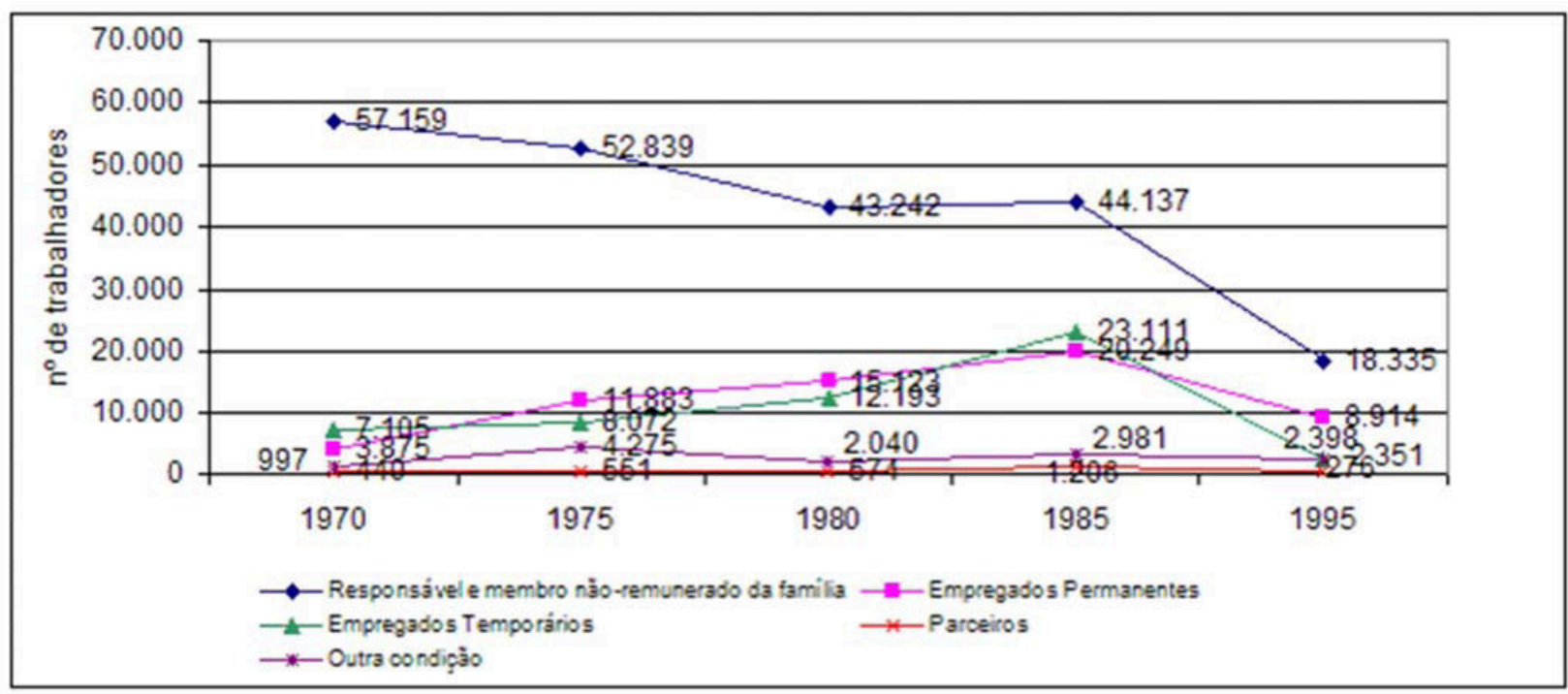

Figura 03 - Número de pessoal ocupado por categoria, Extremo Sul da Bahia, 1970, 1995/96.

Fonte: Censo Agropecuário, 1970, 1975, 1980, 1985, 1995 apud Pedreira (2004).

Por outro lado, observa-se crescimento no número de empregados temporários entre 1970 a 1985 de $225 \%$, saindo de 7.105 em 1970 para 23.111 trabalhadores em 1985. Já em 1995 esse número cai para 2.398 trabalhadores, ou seja, uma redução de 863\%, comparando-se os anos de 1985 e 1995.

Os números que representam a categoria responsável e o membro não remunerado da família passaram de $57.159(82,15 \%)$ em 1970 para 18.335
(56,81\%) em 1995. Segundo Pedreira (2004), esses indicadores assinalam duas faces de um grande processo: o declínio e desagregação de formas de produção camponesa, associado ao crescimento das relações de assalariamento. O autor afirma também, que, segundo relato de um morador da região, à medida que o cultivo do eucalipto avançava, o emprego no campo reduzia, tanto o temporário, quanto o permanente, isso pode ser comprovado pelos números apresentados na Figura 03. Mesmo com 
Reorganização socioeconômica no extremo sul da bahia decorrente da introdução da cultura do eucalipto Thiara Messias de Almeida, Ana Maria Souza dos Santos Moreau,Maurício Santana Moreau, Mônica de Moura Pires, Ednice de Oliveira Fontes, Liliane Matos Góes

aumento da participação desse último, as mudanças nas relações de produção e trabalho não foram decorrentes do incremento no segmento agropecuário, em particular, a silvicultura.

Analisando a composição da mão-de-obra no período de 1970-1995/96 (Figura 03), um fato muito marcante é a perda de importância relativa do trabalho familiar na região, refletindo mudanças que se desencadeiam no caráter da atividade agrícola desse espaço rural expresso pela tendência ao privilégio de relações de trabalho de caráter mais tipicamente capitalista (SILVA, 1993).

Pode-se deduzir pela queda no número da categoria "empregado" que houve uma redução muito grande do emprego no meio rural, em decorrência dos impactos do cultivo de eucalipto. Em conseqüência, têm-se transformações demográficas, em função do incremento populacional de cerca de
40\% no total da população urbana dos municípios analisados.

Desse modo, pode-se observar na Figura 04, que desde o ano de 1980, vem ocorrendo um crescimento significativo da população da região e da população do meio urbano. Isso confirma a idéia acima do deslocamento da população do meio rural para o meio urbano. Nota-se uma nova modificação na tendência de deslocamento da população.

A grande maioria dos habitantes reside nas áreas urbanas dos municípios, o que torna o Extremo Sul à segunda região da Bahia em termos de urbanização (Tabela 06). A região registrou as maiores taxas de crescimento entre as populações urbanas das regiões econômicas do Estado, nos dois períodos em estudo: entre 1980-1991, seu ritmo de crescimento foi de 9,23\% ao ano, e entre 1991-2000, de 4,49\% ao ano (SEI, 2003).

Tabela 06 - População residente segundo domicílios - Extremo Sul da Bahia

\begin{tabular}{lccccc}
\hline \multirow{2}{*}{ Ano } & \multicolumn{5}{c}{ População (hab) } \\
\cline { 2 - 6 } & Urbana & $\%$ & Rural & $\%$ & Total \\
\hline 1980 & 77.828 & 23,1 & 259.631 & 76,9 & 337.459 \\
1991 & 271.394 & 66,9 & 134.101 & 33,1 & 405.495 \\
2000 & 423.943 & 77,3 & 124.833 & 22,7 & 548.776 \\
\hline
\end{tabular}

Fonte: SEI e IBGE - Censos demográficos.

De maneira geral, observa-se um aumento da população entre 1980 e 2000 . Em 1980 eram mais de 330 mil habitantes na região, em 2000 esse número passou para mais de 500 mil habitantes (Tabela 06 e Figura 04), resultante, basicamente, do crescimento da população urbana, uma vez que no período de 1980-2000 a população rural teve uma queda de 51\%, coincidindo com período de expansão da silvicultura pela região. 


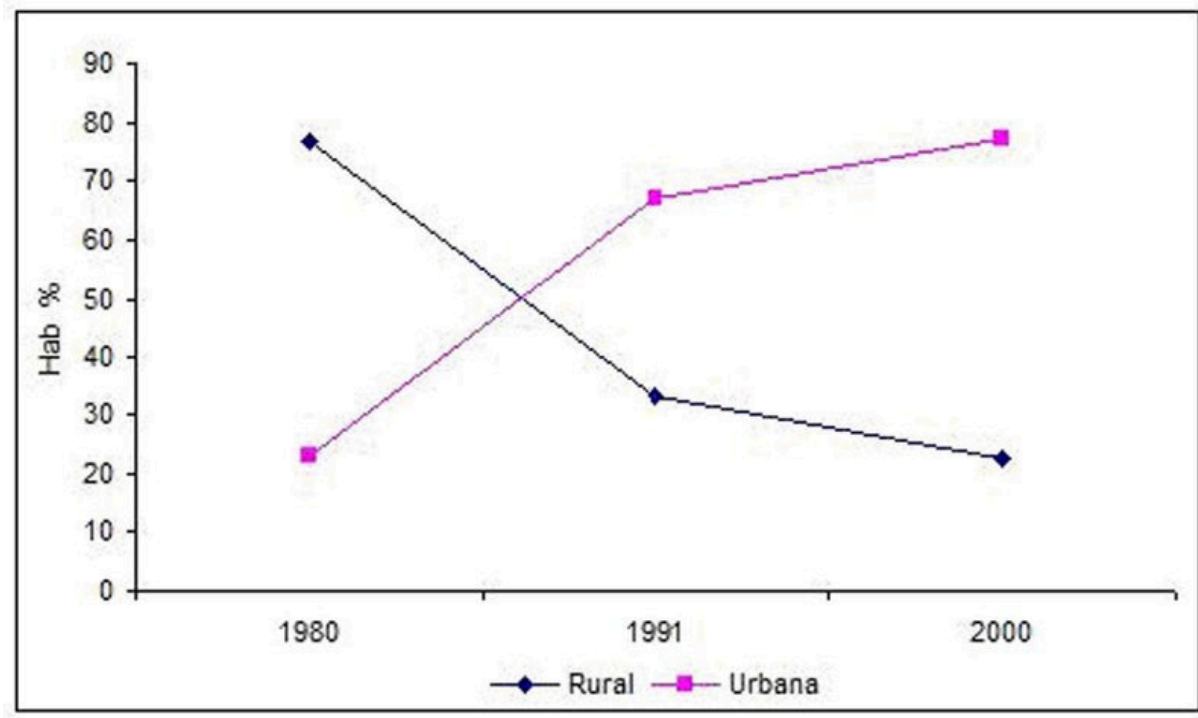

Figura 04 - Comparação da \% da população urbana e rural, Extremo Sul da Bahia 1980-2000

Segundo Machado (1999), até a década de 1980 observa-se um baixo grau de urbanização do Extremo Sul. No entanto, com a privatização do espaço rural, a alternativa para o trabalhador foi o meio urbano, o que ocasionou um aumento dessa população e a conseqüente ocupação de áreas periféricas nas cidades.

A região atinge no ano 2000 uma população urbana de 423.943 habitantes, representando cerca de 77,3\% da população total do Extremo Sul da Bahia. Esse número chega a ser $239,60 \%$ maior que a população rural da região no mesmo período. Tal fato é um reflexo das medidas e condições adotadas no campo. "As ONGs da região consideram que os projetos da indústria de celulose acentuaram o êxodo rural, a migração populacional, inchando as cidades e gerando problemas sociais" (IOS, p. 48, 2005).

Portanto, o fenômeno da urbanização nestas cidades, está relacionado com a perda dos postos de trabalho ou vagas no campo. Contudo, não se pode afirmar que essa população tenha sido alocada em outros tipos de trabalho na cidade. Sendo assim, cabe um questionamento: Quais foram as novas oportunidades de emprego criadas com a expansão da silvicultura no Extremo Sul da Bahia?
Assim, os impactos causados pela implantação do eucalipto na região resultaram em modificações sociodemográficas que culminaram com a transferência da população do campo para cidade, tornando a região mais atrativa, principalmente na geração de emprego. Vale ressaltar que o aumento na oferta de empregos só ocorreu nos períodos de instalação das fábricas.

Nesse contexto, a introdução da monocultura do eucalipto no Extremo Sul da Bahia, conseguiu absorver inicialmente, na fase da sua implantação, grandes quantidades de mão-de-obra, principalmente nos tratos culturais e nas instalações de suas indústrias, decorrido esse primeiro momento, a quantidade de empregos nessas atividades diminuiu significativamente (DIAS, 2001).

\section{CONSIDERAÇÕES FINAIS}

A análise do PIB total e per capita dos municípios objeto da pesquisa e que desenvolvem o cultivo do eucalipto, cresceu após a implantação e expansão da silvicultura, no entanto, poucas são as mudanças sociais verificadas nessas localidades. Tal assertiva pode ser observada pelos valores do IDH, que, na maioria dos municípios, encontra-se abaixo da média estadual e nacional, indicando assim, que 
Reorganização socioeconômica no extremo sul da bahia decorrente da introdução da cultura do eucalipto Thiara Messias de Almeida, Ana Maria Souza dos Santos Moreau,Maurício Santana Moreau, Mônica de Moura Pires,

Ednice de Oliveira Fontes, Liliane Matos Góes

os investimentos e os lucros gerados com o eucalipto ainda não foram suficientes para beneficiar a população da região frente às expectativas geradas.

O que se pode afirmar, é que, a implantação do seguimento de celulose na região provocou a concentração fundiária no campo, diminuição no número de empregados no campo (permanentes e temporários) e do trabalho familiar, que resultou um processo intenso de êxodo rural e uma reorganização socioeconômica. Como conseqüência teve-se o aumento da população urbana, que implicou na busca de empregos e novas oportunidades nas cidades, ocasionando um crescimento desordenado das áreas urbanas, provocando novas paisagens locais.

\section{REFERÊNCIAS}

ATLAS DE DESENVOLVIMENTO HUMANO. Disponível em: <http:// www.pnud.org.br/atlas $>$. Acesso em: 12 jul. 2006.

AVENA, A. (Org.). Bahia Século XXI. Salvador: SEPLANTEC, 2002. 400p.

CARNEIRO, R. A. F. Papel e celulose: retrospectiva e tendências. Bahia análise e dados. Salvador, SEI, v.5, n.3, p.81-86, dez, 1995.

CARNEIRO, R. A. F. A indústria de papel e celulose no Extremo Sul: estágio atual e perspectivas. Bahia: Análise e Dados, Salvador, CEI, v.4, n.2/3, p.206217, dez 1994.

CENTRO DE ESTATÍSTICAS E INFORMAÇÕES - CEI. Perfil da região econômica Extremo Sul. Salvador, 1992. 64p.

COMPANHIA DE DESENVOLVIMENTO E AÇÃO REGIONAL - CAR. Política de desenvolvimento para o extremo sul da Bahia. Salvador; 1994. 142p.

COUTO, E. A. Diagnóstico estratégico do Sul da Bahia. In: Revista eletrônica Cesesb. Itamaraju, 2006. Disponível em: http://www.cesesb.edu.br/site/ arquivos/pdf/revista_eletronica/administracao/3edicao/ diagnosticoetrategico $>$. Acesso em: 15 set. 2006.
DIAS, N. J. Os impactos da moderna indústria no Extremo Sul da Bahia: expectativas e frustrações. Bahia análise e dados. Salvador, SEI, v. 10, n. 4, p. 320-325, mar, 2001.

GONÇALVES, M. T. A indústria de celulose no Brasil: Analise de sua dinâmica no período de 19501992. Vitória. FASE-IBASE, 1992. 407 p.

INSTITUTO BRASILERO DE GEOGRAFIA E ESTATÍSTICA - IBGE. Censos demográficos. Disponível em: http://www.ibge.gov.br. Acessado em: 15 set. 2006.

INSTITUTO BRASILERO DE GEOGRAFIA E ESTATÍSTICA - IBGE. Censos agropecuários: silvicultura. Disponível em: http://www.ibge.gov.br. Acessado em: 15 set. 2006.

INSTITUTO OBSERVATÓRIO SOCIAL - IOS. Responsabilidade social na Veracel Celulose. Disponível em: < htpp://www.sask.fi/media/ noudettavat/Veracel/veracelRelRS_jul2005vfr.pdf $>$, Acessado em 2006. Acesso em: 03 jun. 2006.

LEVY, M. C. T. C. Avaliação do uso atual e potencial da terra como subsídio à planificação do desenvolvimento do Extremo-Sul do Estado da Bahia. 1999. 76p. Relatório (Bolsa CNPq) Universidade Estadual de Santa Cruz - UESC, Ilhéus, 1999.

MACHADO, G. B. Formação regional e movimentos sociais rurais no Extremo Sul da Bahia, nos anos 90. Disponível em: <http:// wwwgipaf.cnptia.embrapa.br/intens/publ/sober/ trab254.pdf> 1999. Acesso em: 05 jun. 2006.

PEDREIRA, M. da S. Complexo florestal, desenvolvimento e reconfiguração do espaço rural: o caso da Região Extremo Sul baiano. Bahia análise e dados, Salvador, v.13, n.4, p.1005-1018, mar 2004.

SANTOS, C. S.; SILVA, J. L. C. Os impactos do plantio de eucalipto e da produção de celulose em comunidades tradicionais no extremo sul baiano. 
Disponível em $<$ http://www.anppas.org.br/encontro/ segundo/papers/GT17/gt17_jose_caetano.pdf $>2004$.

Acesso em: 10 jun. 2006.

SILVA, E. R. Desenvolvimento rural: um estudo sobre a região Extremo Sul da Bahia. 2003. 147p. Dissertação (Pós-graduação em Economia Rural) Universidade Federal do Ceará - UFC, Fortaleza, 1993.

SOUZA, R. L. de; OLIVEIRA, M. J. L de. Desempenho da indústria de papel e celulose de mercado: Brasil e Bahia 1999/2001. Conjuntura \& Planejamento. Salvador, v.1, p. 19-29, 2002.

SMARTWOOD. Resumo público de certificação da Suzano Bahia Sul Celulose S.A. unidade de Mucuri. Certificado no SW-FM/COC-1377, 2004. Disponível em: <http://www.imaflora.org/arquivos/ SUZANO\%20BAHIA\%20SUL_Mucuri.pdf $>$. Acesso em: 03 out. 2006.

SUPERINTENDENNCIA DE ESTUDOS ECONÔMICOS E SOCIAIS DA BAHIA - SEI. Dez anos de economia baiana. Salvador, 2002. 280p.

SUPERINTENDENNCIA DE ESTUDOS ECONÔMICOS E SOCIAIS DA BAHIA - SEI. Dinâmica sociodemográfica da Bahia: 1980-2002. Salvador: SEI, 2003, 2 v, 449p.

SUPERINTENDÊNCIA DE ESTUDOS ECONÔMICOS E SOCIAIS DA BAHIA - SEI. Informações municipais. Disponível em: $<$ http:// www.sei.ba.gov.br>. Acesso em: 10 jul. 2006.

TEIXEIRA, A. C. O. de; ALMEIDA, T. M. de; FERREIRA, E. S. Proposta para uma periodização da história da mesorregião Sul-Baiana. In: Seminário de Iniciação Científica da UESC, 12., 2006, Ilhéus. Anais...Ilhéus, 2006. p. 366-367. 